\title{
Перспективы терапевтического воздействия на сигнальный nymb FGFR
}

\author{
М. Ю. Федянин ${ }^{1}$, Д. Н. Хмелькова ${ }^{2}$, Т. С. Серебрийская ${ }^{2}$, Т. А. Никольская ${ }^{2}$, С. А. Тюляндин ${ }^{1}$ \\ 'Отделение клинической фармакологии и химиотерапии ФГБНУ «Российский онкологический научный центр \\ им. Н. Н. Блохина»; Россия, 115478, Москва, Каширское шоссе, 24; \\ 2Лаборатория трансляционных исследований и персонализированной медицины Центра живых систем ФГАОУ ВПО \\ «Московский физико-технический институт (государственный университет)»; \\ Россия, 141700, Московская обл., Долгопрудный, Институтский пер., 9
}

Контакты: Михаил Юрьевич Федянин fedianinти@таil.ru

\begin{abstract}
Одними из наиболее исследуемых в онкологии биомаркеров являются рецепторы к фактору роста фибробластов (FGFR), а также лиганды к фактору роста фибробластов (FGF). Молекулярные изменения в генах различных представителей семейства FGF или FGFR - довольно частое событие при злокачественных новообразованиях. Определение значимости комплекса FGF-FGFR в процессах канцерогенеза и в прогрессировании опухолей различной нозологии послужило толчком к появлению работ, посвященных поиску возможностей лекарственного воздействия на данный сигнальный путь. С точки зрения терапевтического воздействия на сигнальный путь FGFR возможно блокировать не только лиганды FGF и FGFR, но и нижележсащие молекулы сигнальных путей, активирующихся под действием FGFR. Число ингибиторов тирозинкиназ, селективно блокирующих FGFR, на данный момент крайне невелико. Как правило, тирозинкиназные ингибиторы обладают широким спектром мишеней. Некоторые из таких ингибиторов уже вошли в клиническую практику лечения диссеминированных опухолей различной локализации, другие еще находятся на стадии клинических испытаний. Всего на сайте клинических испытаний clinicaltrials.gov на август 2014 г. зарегистрировано 74 исследования, посвященных изучению ингибиторов FGFR. Способностью ингибировать FGFR обладает также ряд существующих препаратов в высоких концентрациях - сорафениб, вандетаниб, мотесаниб, однако повышение концентрации этих препаратов ассоциировано с выраженной токсичностью лечения. В рекомендованных же терапевтических концентрациях адекватное блокирование тирозинкиназного домена FGFR сомнительно. В статье уделено внимание таким препаратам, как пазопаниб, нинтеданиб, цедираниб, бриваниб, довитиниб, понатиниб. Рассмотрены результаты терапии ингибиторами FGFR при различных нозологиях: рак молочной железы, рак толстой кишки, рак эндометрия, рак желудка, рак щитовидной железы, рак легкого, рак яичников.

Несмотря на то, что анти-FGFR-терапия находится на раннем этапе клинического изучения в онкологии, уже сейчас видны определенные трудности в реализации данного лечебного подхода, такие как высокая токсичность, не всегда валидированная мишень воздействия, необходимость отбора пациентов в зависимости от активности FGF-FGFR-nути, а также наличия мутаций в генах молекул нижележащих сигнальных путей. В обзоре рассмотрены молекулярные процессы, возникающие при активации комплекса FGF-FGFR, а также пути терапевтического воздействия на данный комплекс, результаты исследований и перспективы применения ингибиторов сигнального пути FGFR.
\end{abstract}

Ключевые слова: фактор роста фибробластов, рецепторы к фактору роста фибробластов, канцерогенез, моноклональные антитела, ингибиторы тирозинкиназ, клинические исследования, солидные опухоли, пазопаниб, нинтеданиб, понатиниб

DOI: $10.17650 / 2313-805 X .2015 .2 .1 .027-038$

Prospects of therapeutic action on FGFR signaling pathway

\author{
M. Yu. Fedyanin ${ }^{1}$, D. N. Khmelkova ${ }^{2}$, T. S. Serebriyskaya ${ }^{2}$, T. A. Nikolskaya ${ }^{2}$, S. A. Tyulyandin ${ }^{1}$ \\ ${ }^{1}$ Department of clinical pharmacology and chemotherapy, N. N. Blokhin Russian Cancer Research Center; \\ 24 Kashirskoye Highway, Moscow, 115478, Russia; \\ ${ }^{2}$ Laboratory of Translational Research and Personalized Medicine, Living Systems Center, Moscow Physical \\ and Technical Institute (State University); 9 Institutsky Per., Dolgoprudny, Moscow region, 141700, Russia
}

Fibroblast growth factors (FGFS) and their receptors (FGFRs) are involved in key cellular functions and cancerogenesis. Nowadays FGFR and their ligands are one of the most investigated markers in oncology and targets for specific therapy. There are a lot of clinical trials in oncology include drugs with anti-FGFR activities. The most of these drugs are tyrosine kinase inhibitors and monoclonal antibodies. When we say about therapeutic effects on the FGFR signaling pathway, we say about opportunity not only block the ligands and FGFRs, but the underlying molecular and signaling pathways activated by FGFRs. Nowadays the number of tyrosine kinase inhibitors selectively blocking FGFRs is extremely small. Typically, tyrosine kinase inhibitors can block a wide range of targets. Some of these inhibitors have entered in clinical practice in the treatment of metastatic tumors of different localizations, others are in clinical trials. On August 2014, 74 studies investigating inhibitors of FGFRs are registered on clinicaltrials.gov. A number of marketed drugs at high concentrations also has the ability to inhibit FGFR - sorafenib, vandetanib, motesanib, however, increasing the concentration of these drugs is associated with severe toxicity of treatment. In the recommended therapeutic concentrations, adequate blocking FGFR tyrosine kinase domain is doubtful. The review paid attention to such drugs as pazopanib, nintedanib, cediranib, brivanib, dovitinib, ponatinib. We showed the results of treatment with inhibitors of FGFR in different cancers such as breast cancer, colon cancer, endometrial cancer, gastric cancer, thyroid cancer, lung cancer, ovarian 
cancer. Despite the fact that anti-FGFR therapy are at an early stage of clinical investigation, some difficulties in implementing this therapeutic approach have been seen, such as high toxicity, not validated targets, the need for patient selection, depending on the activity of FGFFGFR pathway, as well as mutations in genes of downstream molecular signaling pathways.

In summary in the article we reviewed relevant literature to identify current status, difficulties and future perspectives in development of antiFGFR drugs. In this article, we review FGFR signaling and describe the therapeutic intervention in patients with solid tumors.

Key words: solid tumors, fibroblast growth factor receptor, fibroblast growth factors, cancerogenesis, monoclonal antibodies, tyrosine kinase inhibitors, clinical trials, pazopanib, nintedanib, ponatinib

\section{Введение}

Одними из наиболее исследуемых в онкологии биомаркеров являются рецепторы к фактору роста фибробластов (fibroblast growth factor receptors, FGFR), а также лиганды к нему (fibroblast growth factor, FGF). При этом молекулярные изменения в генах различных представителей семейства FGF или FGFR могут быть обусловлены появлением активирующих мутаций, транслокаций или амплификаций. Кроме этого, выявляются альтерации в различных изоформах FGFR, нарушение экспрессии корецепторов, подавление активности негативных регуляторов FGFR. Возможности терапевтического воздействия на сигнальный путь FGFR позволяют блокировать не только FGF и FGFR, но и нижележащие молекулы сигнальных путей, aктивирующихся под действием FGFR. В данном обзоре будут рассмотрены молекулярные процессы, возникающие при активации комплекса FGF-FGFR, а также пути терапевтического воздействия на данный комплекс, результаты исследований и перспективы применения ингибиторов сигнального пути FGFR.

\section{Факторы роста фибробластов, ux рецеnторы}

\section{u сuгнальные nymu}

Семейство человеческого FGF включает 22 белковых молекулы. По принципу действия их можно разделить на следующие группы:

- лиганды к FGFR: FGF1-10, 16-23;

- лиганды, обладающие ауто- и/или паракринным действием: FGF1-10, 16-18, 20, 22;

- лиганды, функционирующие как гормоны: FGF19, 21, 23;

- факторы, не способные связываться с рецепторами, также известные как FGF-гомологичные факторы: FGF11-14. Они действуют внутри клеток. Предполагается, что белки этой группы участвуют в регуляции работы мембранных натриевых каналов [1, 2].

FGF - многофункциональные белки, играющие важнейшую роль как в эмбриогенезе, так и в жизнедеятельности взрослого организма. Они участвуют в процессах дифференцировки и пролиферации клеток различных типов, а также в регуляции клеточной миграции и выживания, регенерации тканей, в процессах ангиогенеза и нейрогенеза. Множество данных также свидетельствует о том, что нарушенный сигнальный путь FGF может приводить к развитию опухолей $[3,4]$.
FGF воздействуют на клетки через группу рецепторов (FGFR). У человека описано 4 функционально активных рецептора к семейству белков FGF (FGFR1-4). У пятого рецептора, FGFR5, отсутствует тирозинкиназный домен, в связи с чем он, будучи способным связывать молекулы FGF, не проводит сигнал внутрь клетки, выступая, таким образом, как негативный регулятор сигнального пути FGF [3, 5].

FGF - это секретируемые гликопротеиды, однако их локализация может быть различной: они обнаруживаются как во внеклеточном матриксе, так и в цитоплазме, а также в ядре клетки. Находясь в экстрацеллюлярном пространстве, FGF образуют комплексы с гепаринсульфат-протеогликанами (ГСП) матрикса. Взаимодействие с рецептором на поверхности клетки возможно только при высвобождении молекулы FGF из комплекса с ГСП; этот процесс обеспечивается гепариназами и протеазами внеклеточного матрикса. После высвобождения молекула FGF связывается с ГСП на мембране клетки, что облегчает дальнейшее образование лиганд-рецепторного комплекса с FGFR [3].

Обнаружение FGF (а также их рецепторов) в ядре клетки позволило предположить, что они также могут регулировать процессы жизнедеятельности клеток через механизмы, отличные от классического тирозинкиназного сигнального пути [6, 7].

Наиболее изученными представителями описанного семейства факторов роста являются FGF1 и FGF2. FGF1 - единственный фактор из всего семейства, который с высокой аффинностью способен связываться со всеми изоформами FGFR; все остальные FGF проявляют специфичность к изоформам FGFR. FGF1 играет роль в процессах ангиогенеза и адипогенеза [5, 8].

FGF2 вовлечен в регуляцию основных процессов существования клетки: пролиферации, дифференцировки, выживания, клеточной адгезии, миграцию, подвижности и апоптоза. In vivo FGF2 регулирует процессы формирования конечностей, заживления ран, ангиогенеза, васкулогенеза и ремоделирования кровеносных сосудов, а также участвует в процессах канцерогенеза. FGF2 проявляет митогенную и хемоаттрактивную активность в отношении эндотелиоцитов и клеток гладкой мускулатуры сосудов, а также активирует пролиферацию перицитов. Следует отметить, что FGF2 стимулирует образование активатора плазминогена и экспрессию металлопротеиназ, играя важную роль в процессах сосудистой стабилизации и моделирования экстрацеллюлярного матрикса [5, 8]. 
Однако его активность проявляется лишь в совокупности с работой других факторов. Показано, что при выключении гена $F G F 2$ у мышей сохраняется способность к нормальному ангиогенезу, отмечаются незначительные нарушения в формировании скелета и сердечно-сосудистой и нервной систем $[9,10]$.

Различные эффекты белков семейства FGF на клетку определяются лиганд-специфичностью соответствующих рецепторов и их изоформ, а также тканеспецифичностью их экспрессии. Структурно молекула рецептора состоит из экстрацеллюлярной части, включающей в себя 3 иммуноглобулин-подобных домена, способных связываться с FGF, трансмембранного перешейка и цитоплазматического внутриклеточного тирозинкиназного домена. В результате альтернативного сплайсинга третьего иммуноглобулин-подобного домена образуются 2 группы изоформ FGFR: IIIB и IIIC.
Исключение составляет FGFR4, который экспрессируется только в виде изоформы IIIC. Интересно отметить, что экспрессия изоформ рецепторов имеет тканеспецифичный характер. Так, изоформы IIIB обнаружены преимущественно в эпителиальных тканях, тогда как изоформы IIIC характерны для клеток соединительной ткани. Большинство из FGF могут активировать несколько рецепторов, за исключением FGF7, который способен связываться только с IIIBизоформой FGFR2 [3, 5].

FGF осуществляют свои функции в клетке через классический сигнальный путь, включающий в себя активацию сигнальных каскадов РІ3К/АKТ, МАРК, PLC $\gamma$, а также транскрипционных факторов STAT (рис. 1). После связывания с лигандом FGFR могут формировать как гомодимеры, так и гетеродимеры. Димеризация рецептора и интернализация лиганда необходимы

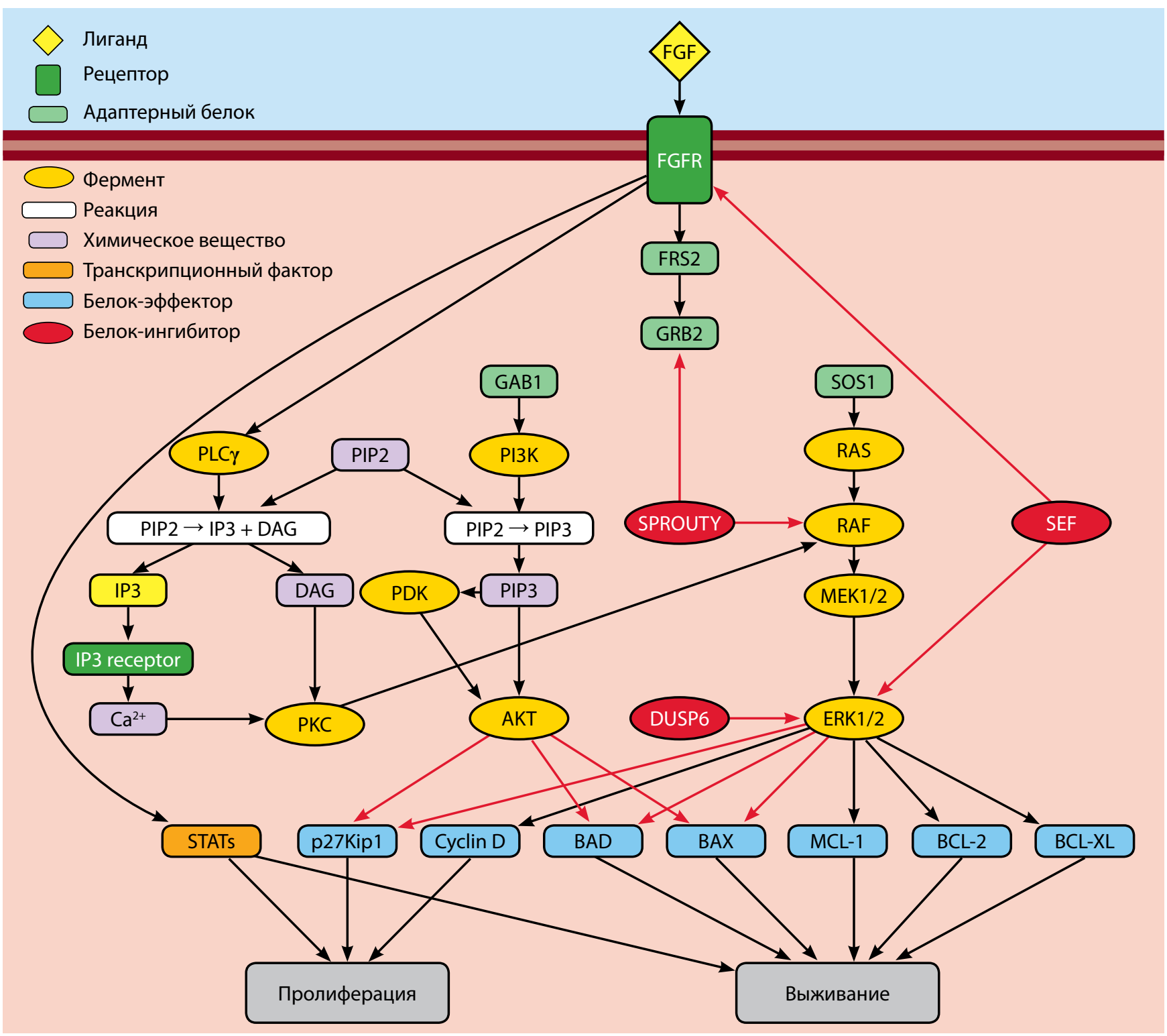

Рис. 1. Сигнальный путь FGF 
для дальнейшей передачи FGF-сигнала в клетку. В данных процессах участвуют ГСП, экспрессированные на мембране клетки (например, синдеканы и глипиканы) $[3,11]$. Связывание лиганда с рецептором приводит к димеризации FGFR и последующей активации его тирозинкиназного домена. Остатки тирозина в киназном домене служат местом посадки адаптерных белков, главным из которых является FRS2. Связывание FRS2 c FGFR приводит к фосфорилированию адаптерной молекулы за счет киназной активности рецептора. Фосфорилирование FRS2 в свою очередь приводит к активации MAPK-каскада RAS-RAF-MEK1/2ERK1/2 через дополнительные адаптерные молекулы GRB2 и SOS1, а также к активации фосфатидилинозитол-3-киназы (РI3K) через адаптер GAB1. PI3К в свою очередь запускает реакцию образования фосфатидилинозитол-3-фосфата (РIP3) из фосфатидилинозитол2-фосфата (PIP2). PIP3 совместно с киназой PDK активирует еще одну киназу - AKT $[3,12,13]$. Активация пути RAS-RAF-MEK-ERK приводит к усилению экспрессии циклина D [3, 14-16]. Кроме того, активация как пути RAS-ERK, так и пути PI3K-AKT ведет к подавлению активности ингибитора циклинзависимой киназы р27 ${ }^{\mathrm{KIP} 1}[17,18]$. Это определяет усиление пролиферации клетки. Активация как пути RAS, так и пути PI3K способствует выживанию клетки в стрессовых условиях в результате ингибирования апоптотических белков, таких как BAD и BAX [3, 19, 20]. Кроме этого, клетка «ускользает» от апоптоза путем активации антиапоптотических белков MCL-1, BCL-2 и BCL-XL [3, 19, 21].

Адаптер-независимым путем происходит взаимодействие между остатками тирозина в киназном домене FGFR и SH2-доменом фосфолипазы C $\gamma$, что приводит к ее активации [22]. Данная фосфолипаза катализирует реакцию превращения РIP2 в инозитол3-фосфат (IP3) и диацилглицерол (DAG). IP3 связывается со своим рецептором в мембране эндоплазматического ретикулума (ЭПР), что в итоге приводит к открытию кальциевых каналов и выходу ионов кальция из ЭПР в цитоплазму. DAG и кальций необходимы для активации протеинкиназы C, которая в свою очередь способствует дополнительной активации МАРКпути за счет фосфорилирования RAF [3]. Четвертый сигнальный путь, который могут активировать FGFR, STAT (signal transduction and activation of transcription), приводящий к экспрессии генов, ответственных за такие клеточные процессы, как рост, дифференцировка, апоптоз [3, 23].

В регуляции активности сигналов FGFR участвуют различные молекулы:

- DUSP6 (инактивирует ERK);

- белок SPROUTY (ингибирует GRB2 и RAF (BRAF и/или CRAF), приводя к инактивации пути RASERK);

- SEF (подавляет фосфорилирование FGFR, ингибирует ERK) [24-26].
В норме FGFR отвечают за развитие костносуставной системы у позвоночных, участвуя в регуляции дифференцировки и пролиферации остеобластов и хондроцитов. Повышенная активность сигнального пути FGF у эмбрионов и детей приводит к развитию аномалий скелета, включая карликовость и краниосиностозные синдромы, ахондроплазии. Во взрослом организме FGF вовлечены в процессы физиологического и патологического ангиогенеза. Нарушения в системе FGF-FGFR наблюдаются также при болезни Альцгеймера, мышечной дистрофии Дюшена, диабетической ретинопатии, атеросклерозе [27].

В большом количестве работ отмечаются изменения активности лиганд-рецепторного комплекса FGFFGFR в опухолевых клетках. При этом гиперэкспрессия различных представителей семейств FGF и FGFR может быть обусловлена появлением активирующих мутаций, транслокаций или амплификаций соответствующих генов. Также выявлены альтерации в различных изоформах FGFR, нарушения экспрессии корецепторов, подавление активности негативных регуляторов FGFR - например, SPROUTY [28].

Изменения в системе FGF-FGFR наиболее выражены при таких злокачественных опухолях, как рак мочевого пузыря, рак молочной железы (РМЖ), рак толстой кишки. Более подробно об изменениях в системе FGF-FGFR рассказано в обзоре [29]. Значимость изменений в комплексе FGF-FGFR в процессе канцерогенеза определяет актуальность и необходимость изучения путей терапевтического воздействия на данный комплекс. Ниже представлены результаты исследований и перспективы применения ингибиторов сигнального пути FGFR.

\section{Ингибиторы тuрозинкиназ FGFR}

В настоящее время основными препаратами таргетной терапии являются моноклональные антитела к рецепторам и их лигандам, а также малые молекулы, ингибирующие тирозинкиназную активность белков, в том числе рецепторов. Число ингибиторов тирозинкиназ, селективно блокирующих FGFR, на данный момент крайне невелико. Как правило, тирозинкиназные ингибиторы обладают широким спектром мишеней. Некоторые из таких ингибиторов уже вошли в клиническую практику лечения диссеминированных опухолей различной локализации, другие еще находятся на стадии клинических испытаний (таблица, рис. 2). Всего на сайте клинических испытаний clinicaltrials.gov на август 2014 г. зарегистрировано 74 исследования, посвященных изучению ингибиторов FGFR.

Ряд существующих препаратов в высоких концентрациях также обладают способностью ингибировать FGFR - сорафениб, вандетаниб, мотесаниб, однако повышение концентрации этих препаратов ассоциировано с выраженной токсичностью лечения. В рекомендованных же терапевтических концентрациях 
Препараты, одной из мишеней которых является FGFR

\begin{tabular}{|c|c|c|c|}
\hline Препарат & Производитель & Спектр рецепторов-мишеней & Стадия разработки \\
\hline Пазопаниб & GSK & VEGFR1-3, PDGFR, FGFR, CSF1R & В клинике \\
\hline Понатиниб & ARIAD Pharmaceuticals & BCR-ABL, FGFR & В клинике \\
\hline Цедираниб & AstraZeneca & VEGFR1-3, KIT, PDGFR, FGFR, Src, CSF1R & III фаза \\
\hline Бриваниб аланинат & BMS & VEGFR2, FGFR1-3 & III фаза \\
\hline Нинтеданиб (BIBF1120) & Boehringer Ingelheim & VEGFR1-3, FGFR1-3, PDGFR $\alpha, \beta$, Src, Lck, Lyn & III фаза \\
\hline Довитиниб & Chiron/Novartis & FGFR, FLT3, KIT, PDGFR, VEGFR & III фаза \\
\hline Маситиниб & AB Science & KIT, PDGFR, FGFR & III фаза \\
\hline AZD4547 & AstraZeneca & FGFR & II фаза \\
\hline СР-547632 & OSI/Pfizer & VEGFR2, FGFR & II фаза \\
\hline Люцитаниб & Clovis Oncology, Inc & VEGFR, FGFR, PDGFR & II фаза \\
\hline BGJ398 & Novartis Pharmaceuticals & FGFR & II фаза \\
\hline Данусертиб & NMS Oncology & Aurora A/B/C, Abl, TrkA, RET, FGFR1 & II фаза \\
\hline XL999 & Symphony Evolution, Inc & VEGFR2, PDGFR $\beta$, FLT3, FGFR1,3, RET, KIT & II фаза \\
\hline Orantinib (TSU-68) & Taiho Pharmaceutical Co., Ltd. & VEGFR, PDGFR, FGFR & II фаза \\
\hline ARQ 087 & ArQule & FGFR & І фаза \\
\hline XL228 & Exelixis & IGF1R, Src, FGFR, BCR-ABL & І фаза \\
\hline Sulfatinib (HMPL-012) & Hutchison MediPharma, Ltd & VEGFR1-3, FGFR & І фаза \\
\hline $\mathrm{R}-1530$ & Roche & VEGFR, FGFR, PDGFR & І фаза \\
\hline Debio-1347 & Debiopharm International SA & FGFR & І фаза \\
\hline BAY1163877 & Bayer & FGFR & І фаза \\
\hline JNJ-42756493 & $\begin{array}{c}\text { Janssen Research \& Development, } \\
\text { LLC }\end{array}$ & FGFR & І фаза \\
\hline PD173074 & Pfizer & FGFR1 & I фаза \\
\hline Е7080 (ленватиниб) & Eisai & FGFR, PDGFR, VEGFR & І фаза \\
\hline FP-1039 & Five Prime Therapeutics, Inc & FGF (моноклональное антитело) & II фаза \\
\hline BAY1179470 & Bayer & FGFR2 (моноклональное антитело) & І фаза \\
\hline GSK3052230 & GlaxoSmithKline & FGFR1 (моноклональное антитело) & I фаза \\
\hline
\end{tabular}

адекватное блокирование тирозинкиназного домена FGFR сомнительно. Большинство ингибиторов тирозинкиназ способны подавлять фосфорилирование тирозинкиназ различных молекул. В связи с этим блокируется не только FGFR, но зачастую также VEGFR и PDGFR, что обусловлено схожестью тирозинкиназных доменов данных рецепторов. Это, с одной стороны, усиливает эффект препаратов, а с другой - расширяет спектр осложнений лечения.

Ряд препаратов был исключен из исследований в связи с неприемлемой токсичностью. Так, препарат XL999 в I фазе клинических испытаний показал выраженную сердечную токсичность. Другой препарат (PD173074), обратимый ингибитор тирозинкиназ
FGFR1-3, проявил выраженную антипролиферативную активность на FGFR2-экспрессирующих клеточных линиях рака эндометрия [30], рака желудка [31, 32], однако показал неприемлемую токсичность [32]. Классический спектр осложнений, характерных для ингибиторов FGFR, хорошо иллюстрируют результаты I фазы испытаний препарата TKI-258 (довитиниб - мультитирозинкиназный ингибитор VEGFR, PDGFR, FGFR1-3, FLT3 и KIT). Спектр побочных явлений включал слабость, артериальную гипертензию, тошноту, рвоту, отсутствие аппетита, диарею. Часть осложнений купировались назначением сопроводительной терапии, другие осложнения удалось скорректировать за счет снижения дозы препарата [33]. 


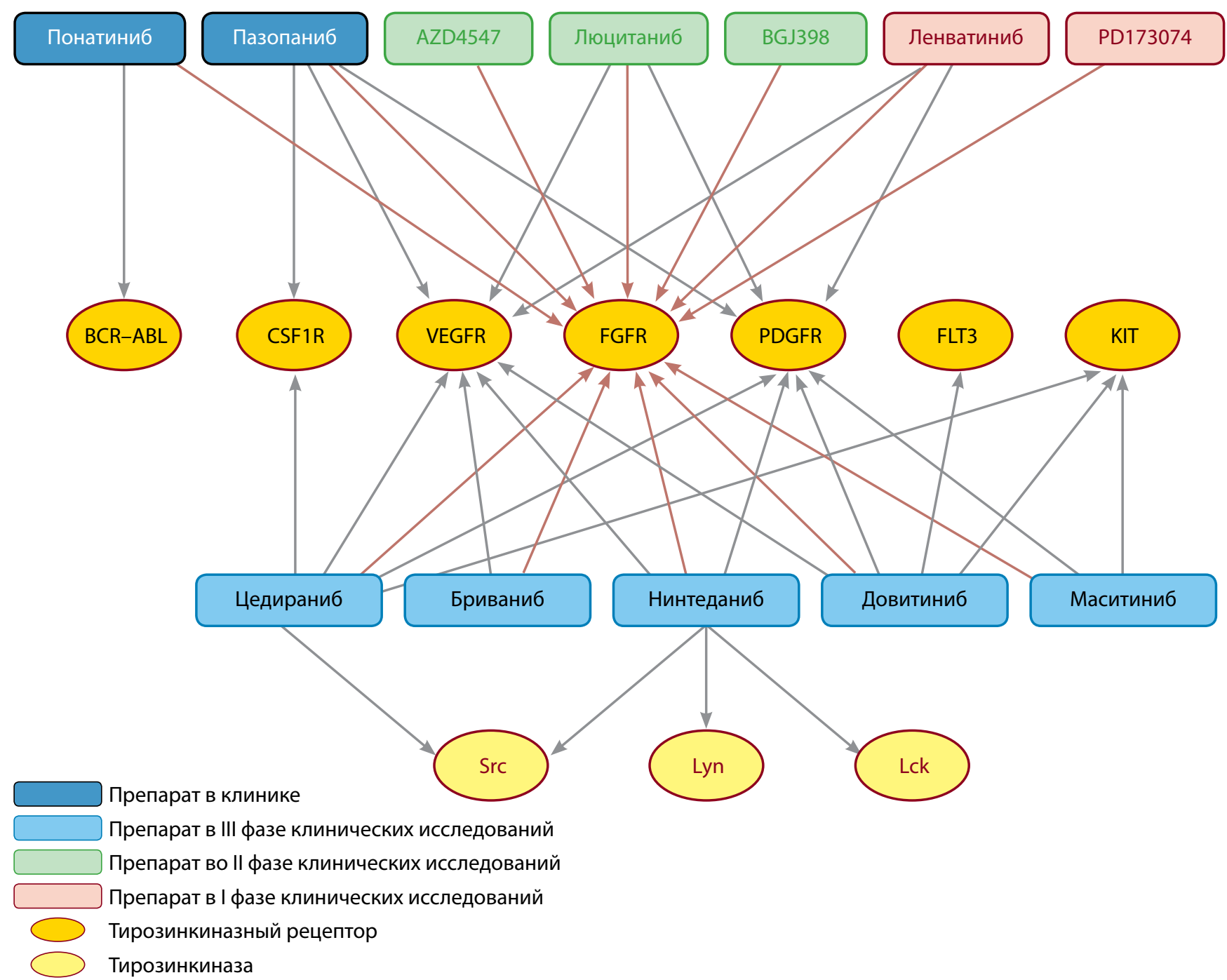

Рис. 2. Перспективные ингибиторы тирозинкиназ и их мишени

В ряде случаев исследования, для которых шел отбор пациентов по наличию мутации в генах $F G F R$, закрывались досрочно в связи с крайне медленным набором. К примеру, в исследование препарата FP-1039 предполагалось включать больных раком эндометрия с мутациями в гене $F G F R 2$. Из 70 скринированных пациенток никого не удалось включить в исследование (clinicaltrials.gov).

Рассмотрим эффективность уже зарегистрированного препарата с анти-FGFR-действием - пазопаниба. В настоящее время пазопаниб зарегистрирован для применения в 1-й линии лечения больных диссеминированным раком почки, а также пациентов с рефрактерными к химиотерапии саркомами мягких тканей. В 2010 г. были представлены результаты II фазы исследования терапии пазопанибом больных метастатическим РМЖ. Большинство больных (70 \%) имели гормонопозитивные опухоли. Отметим, что именно при этом подтипе РМЖ чаще всего выявляются изменения в системе FGF-FGFR [29]. Медиана числа линий химиотерапии до начала лечения пазопанибом составила 2. Препарат показал не впечатляющие результаты: объективный ответ наблюдался лишь у 5 \% больных, медиана времени до прогрессирования составила 5,3 мес. Поданализ в зависимости от статуса гена $F G F R$ не проводился [34]. Кроме того, опубликованы результаты рандомизированного исследования II фазы по применению комбинации пазопаниба или плацебо с лапатинибом или монотерапии пазопанибом у больных метастатическим РМЖ с гиперэкспрессией рецептора HER-2/neu с прогрессированием после как минимум 1 линии химиотерапии. Применение комбинации пазопаниба и лапатиниба было ассоциировано с повышением частоты объективных ответов опухоли, но не с увеличением времени до прогрессирования в сравнении с монотерапией лапатинибом. Применение комбинированного режима также было ассоциировано с увеличением числа осложнений IIIIV степени и, как следствие, более частым снижением дозы препаратов [35].

В настоящее время зарегистрировано 16 исследований пазопаниба при РМЖ, часть из которых 
уже завершена. При этом ни в одном из них не проводился отбор пациентов с гиперэкспрессией белков FGFR в опухоли. Только в одном исследовании ставилась задача изучения пациенток с гормональнозависимым заболеванием (пазопаниб + экземестан), однако оно было закрыто еще до начала включения больных. В связи с тем, что таргетная терапия воздействует на опухоль при наличии в ней мишени, для всей популяции пациентов она может оказаться незначимо эффективной. Принимая во внимание распространенность нарушений в системе FGFFGFR, особенно при дольковом РМЖ, а также при развитии резистентности к гормонотерапии [29], нам видится, что именно эта популяция больных должна рассматриваться в качестве мишени для разработки препаратов целенаправленного действия против FGFR.

При раке толстой кишки проведено 2 исследования I фазы: комбинации пазопаниба и FOLFOX/ XELOX и режима пазопаниб + иринотекан + цетуксимаб. Доступны результаты первого исследования. Доказав удовлетворительную переносимость изучаемой комбинации, авторы отметили, что частота объективных ответов для режима пазопаниб + FOLFOX составила $40 \%$, для комбинации пазопаниба с режимом XELOX - $38 \%$ [36]. При этом только $16 \%$ больных получали предшествующую химиотерапию. Таким образом, добавление пазопаниба к химиотерапии больных раком толстой кишки значимо не улучшило результаты лечения. В настоящее время не зарегистрировано других исследований с пазопанибом при раке толстой кишки. Интересным видится более персонализированный подход для отбора пациентов в исследование: при прогрессировании после оксалиплатин-содержащей химиотерапии 1-й линии в случае наличия гиперэкспрессии белка FGFR4 вновь исследовать эффективность режима FOLFOX/XELOX в комбинации с пазопанибом.

Еще одним хорошо изученным препаратом с антиFGFR-активностью является препарат бриваниб. Это ингибитор тирозинкиназ рецепторов VEGFR, PDGFR, FGFR. При изучении препарата на ксенографтных моделях гормонопозитивного РМЖ схема тамоксифен + бриваниб оказывала более выраженное антипролиферативное действие, нежели монотерапия каждым из препаратов [37]. При этом на группе клеток с гиперэкспрессией белка FGFR1 бриваниб был более эффективным, оказывая прямой антипролиферативный, а не только антиангиогенный эффект [38]. В настоящее время клинических исследований с бриванибом при РМЖ не зарегистрировано. В исследовании III фазы у больных с метастатическим рефрактерным раком толстой кишки с диким типом гена $K R A S$ проведено сравнение комбинации цетуксимаба с бриванибом или плацебо. В исследование были включены 750 больных. Медиана продолжительности жизни составила 8,8 мес в группе с бриванибом и 8,1 мес в груп- пе с плацебо (относительный риск (ОР) 0,88; $95 \%$ доверительный интервал (ДИ) $0,74-1,03 ; p=0,12$ ). Медиана времени до прогрессирования составила 5,0 и 3,4 мес соответственно (ОР 0,72; 95 \% ДИ 0,62-0,84; $p<0,0001)$. И частичные ответы $(13,6$ против $7,2 \%$; $p=0,004)$, и стабилизация (50 против $44 \%$ ) наблюдались чаще в группе с бриванибом. Частота осложнений $\geq$ III степени была выше в группе комбинации цетуксимаба с бриванибом (78 против $53 \%$ ). У пациентов, получавших бриваниб, чаще развивались астения $(25 \%)$, артериальная гипертензия (11\%) и сыпь (10 \%) [39]. Назначение бриваниба всем больным не привело к улучшению выживаемости. В 2011 г. было инициировано исследование комбинации бриваниба и иринотекана у больных метастатическим раком толстой кишки с высоким уровнем FGF в плазме крови. Однако исследование было прекращено спонсором без объяснения причины (clinicaltrials.gov). Добавление бриваниба к режимам FOLFOX и FOLFIRI неожиданно для исследователей привело к большому числу тромботических осложнений [40].

Цедираниб - это тирозинкиназный ингибитор, который наряду с FGFR, VEGFR1-3 блокирует еще и KIT. В исследовании HORIZON II в качестве 1-й линии терапии метастатического рака толстой кишки было проведено сравнение режимов FOLFOX/XELOX + цедираниб и FOLFOX/XELOX + плацебо. Заключительные результаты исследования не показали статистически значимых различий между группами с цедиранибом и плацебо в отношении показателей продолжительности жизни (ОР 0,$94 ; p=0,571)$ [41]. Однако препарат, возможно, займет свою нишу в лечении больных раком яичников - получены обнадеживающие результаты в III фазе исследования [42], хотя, по-видимому, противоопухолевый эффект при раке яичников препарат оказывает за счет своего антиангиогенного, а не анти-FGFR-действия.

BIBF1120 (нинтеданиб) - мультитаргетный ингибитор тирозинкиназ, который наряду с блокированием VEGFR1-3 и FGFR2 оказывает воздействие и на такие мишени, как киназы Lck, Lyn и Src. B ряде исследований I фазы при ежедневном приеме препарата в качестве дозолимитирующей токсичности выступало транзиторное повышение трансаминаз печени. Другими наиболее часто встречающимися осложнениями были реакции со стороны желудочно-кишечного тракта: тошнота, рвота, диарея и астения. Отмечены длительные периоды стабилизации при различных опухолях - до 4-11 мес [43-47]. Интересные результаты были достигнуты и во II фазе исследования в комбинации с химиотерапевтическими режимами при немелкоклеточном раке легкого и раке яичников [48, 49]. В работах I/II фазы отмечена приемлемая переносимость и эффективность комбинации BIBF1120 с бевацизумабом при раке толстой кишки. Однако в комбинации с афатинибом при раке толстой кишки или в комбинации с EGFR-ингибитором (BIBW2992) 
при раке предстательной железы препарат не показал значимых эффектов [50, 51]. В настоящее время в онкологии зарегистрировано 4 исследования III фазы с препаратом BIBF1120:

- комбинация с доцетакселом во 2-й линии терапии немелкоклеточного рака легкого;

- комбинация с пеметрекседом во 2-й линии терапии немелкоклеточного рака легкого;

- комбинация с паклитакселом и карбоплатином в 1-й линии терапии рака яичников;

- в монорежиме при химиорефрактерном раке толстой кишки.

В исследовании III фазы при раке яичников добавление исследуемого препарата не привело к увеличению выживаемости больных [52]. Между тем при применении его в комбинации с доцетакселом во 2-й линии лечения больных немелкоклеточным раком легкого время до прогрессирования было статистически значимо выше, чем в случае комбинации доцетаксела с плацебо. Однако риск смерти для всей исследуемой популяции больных в группе с BIBF1120 снизился лишь на $6 \%$ (OP 0,94; $p=0,2)$ [53]. При этом ни в исследованиях I фазы, ни в 25 проводящихся исследованиях II фазы и 4 исследованиях III фазы не применяется дифференцированный отбор пациентов по экспрессии предполагаемых мишеней воздействия препаратов, в том числе и FGF-FGFR.

Большие надежды возлагались на препарат довитиниб, имеющий другой спектр мишеней, - наряду c FGFR он блокирует FLT3, KIT и CSF1R. Наиболее часто встречаемый вариант осложнений терапии довитинибом - слабость и гастроинтестинальная токсичность [33]. На ESMO 2014 были представлены результаты исследования довитиниба у больных раком эндометрия во 2-й линии лечения в зависимости от наличия мутации в гене FGFR2. Для включения в исследование 31 пациентки с диким типом гена FGFR2 и 22 больных с мутацией в гене было скринировано 248 пациенток. Частота выявления мутаций составила $11 \%$. Статистический дизайн предполагал, что имеет смысл продолжать набор больных, если хотя бы у 8 из первых 20 пациенток, включенных в исследование, время до прогрессирования составит более 18 нед. Однако только у 5 пациенток в группе без мутации и у 7 в группе с мутацией была достигнута выживаемость без прогрессирования 18 нед. В связи с этим исследование было прекращено. Однако были получены неожиданные результаты: объективный эффект от применения ингибитора FGFR2 (довитиниба) оказался выше в группе больных без мутации в гене FGFR2 (16 против 5 \%), время до прогрессирования не различалось между группами. Тем не менее медиана продолжительности жизни была выше в группе с мутацией (20,2 против 9,3 мес). У 68 \% больных развившиеся побочные эффекты потребовали перерыва в терапии довитинибом или снижения дозы препарата. Основной причиной прекращения лечения в связи с токсичностью явились тромбоэмболические осложнения. С одной стороны, препарат показал активность у больных раком эндометрия, с другой - роль мишени (мутация FGFR2), на которую должен был бы воздействовать препарат, не подтвердилась [54]. Результаты исследования II фазы довитиниба у больных РМЖ, положительным по рецепторам эстрогенов (ER), с гиперэкспрессией FGFR оказались не впечатляющими. Однако отмечена некоторая тенденция к большей эффективности препарата при амплификации гена FGFR [55]. В настоящее время препарат исследуется при РМЖ, раке мочевого пузыря, почки, множественной миеломе.

В ходе изучения эффективности тирозинкиназных ингибиторов при РМЖ был отмечен выраженный антипролиферативный эффект на клеточных линиях РМЖ с амплификацией генов FGFR1 или FGFR2 при применении препаратов PD173074 и TKI168 [16, 56]. Перспективным видится и комбинированное ингибирование FGFR и HER-2/neu, гиперэкспрессия которых наблюдается зачастую симультанно при РМЖ. В ряде предклинических работ была показана эффективность данного воздействия на клеточные линии опухоли [57]. Также в настоящее время продолжается исследование II фазы препарата люцитаниба (мультитирозинкиназный ингибитор VEGFR, FGFR, PDGFR) у больных с ER-положительным РМЖ в зависимости от экспрессии FGFR1 в опухоли [58].

K ингибиторам FGFR также относится препарат понатиниб, показывающий более значимую (в 2-13 раз выше) ингибирующую активность в сравнении с бриванибом, цедиранибом, довитинибом и BIBF1120. При этом препарат оказывает выраженный антипролиферативный эффект при различных опухолях in vitro [59].

Препарат ленватиниб, относящийся к тирозинкиназным ингибиторам VEGFR и FGFR, показал обнадеживающие результаты в терапии больных раком щитовидной железы [60]. В настоящее время проводится изучение препарата в рамках III фазы исследования при данной патологии. Также препарат проходит апробацию при меланоме и гепатоцеллюлярном раке.

Интересными молекулами, селективно ингибирующими FGFR1-4, являются препараты AZD4557 и ВJC398. Эти препараты оказывают выраженный антипролиферативный эффект в большинстве клеточных линий опухолей с гиперэкспрессией компонентов FGF-FGFR [61]. В настоящее время проводятся исследования I/II фазы с AZD4557 при РМЖ и раке желудка с гиперэкспрессией FGFR1 и 2. Молекула ВJC398 находится на I фазе изучения [61, 62].

\section{Моноклональные антитела}

Моноклональные антитела связывают либо лиганд, либо экстрацеллюлярную часть рецептора и действуют более селективно, нежели ингибиторы тирозинкиназ. В связи с этим предполагается, что их 
применение будет ассоциировано с меньшей токсичностью и более высокой эффективностью. В настоящее время исследуются как моноклональные антитела к FGF, так и антитела к FGFR. Более того, есть возможность создать антитела, специфически связывающие определенный тип и даже изоформу FGFR. Моноклональные антитела к FGFR3 показали антипролиферативную активность в отношении клеточных линий уротелиального рака [63] и множественной миеломы с гиперэкспрессией мембранной формы FGFR3. При этом активность в отношении клеток, не экспрессирующих рецептор FGFR3 на мембране, была минимальной [64].

Примером моноклонального антитела к FGF служит FP1039 - белковая молекула, состоящая из внеклеточной части FGFR1-IIIc и Fc-домена иммуноглобулина G1. Данный препарат способен предотвращать связывание различных FGF с их рецепторами. При этом FР1039 показывает антипролиферативный и антиангиогенный эффект на клеточных линиях злокачественных опухолей [65].

Интересно отметить, что в гематологии зарегистрирован препарат, активирующий FGFR, - реком- бинантный лиганд FGF7. Показанием к его назначению являются мукозиты, вызванные химиотерапией при трансплантации стволовых клеток.

\section{Проблемы селективного ингибирования комплекса FGF-FGFR}

Разработка лекарственных препаратов, нацеленных на селективное ингибирование FGFR и FGF, является важной задачей современной онкологии. Однако, даже будучи введенными в клиническую практику, подобные препараты могут иметь ограниченную эффективность при лечении пациентов с мутациями в нижележащих молекулах сигнальных путей, активирующихся под действием FGFR. Два важнейших сигнальных пути, запускаемых комплексом FGFFGFR, - это PI3K/AKT и Ras/Raf/MEK/ERK [3]. Согласно базе данных соматических мутаций при раке COSMIC (http://cancer.sanger.ac.uk/cancergenome/projects/cosmic/), частота встречаемости мутаций в генах этих сигнальных путей весьма высока в различных типах злокачественных опухолей (рис. 3). Так, частота встречаемости мутаций в гене $K R A S$ может достигать

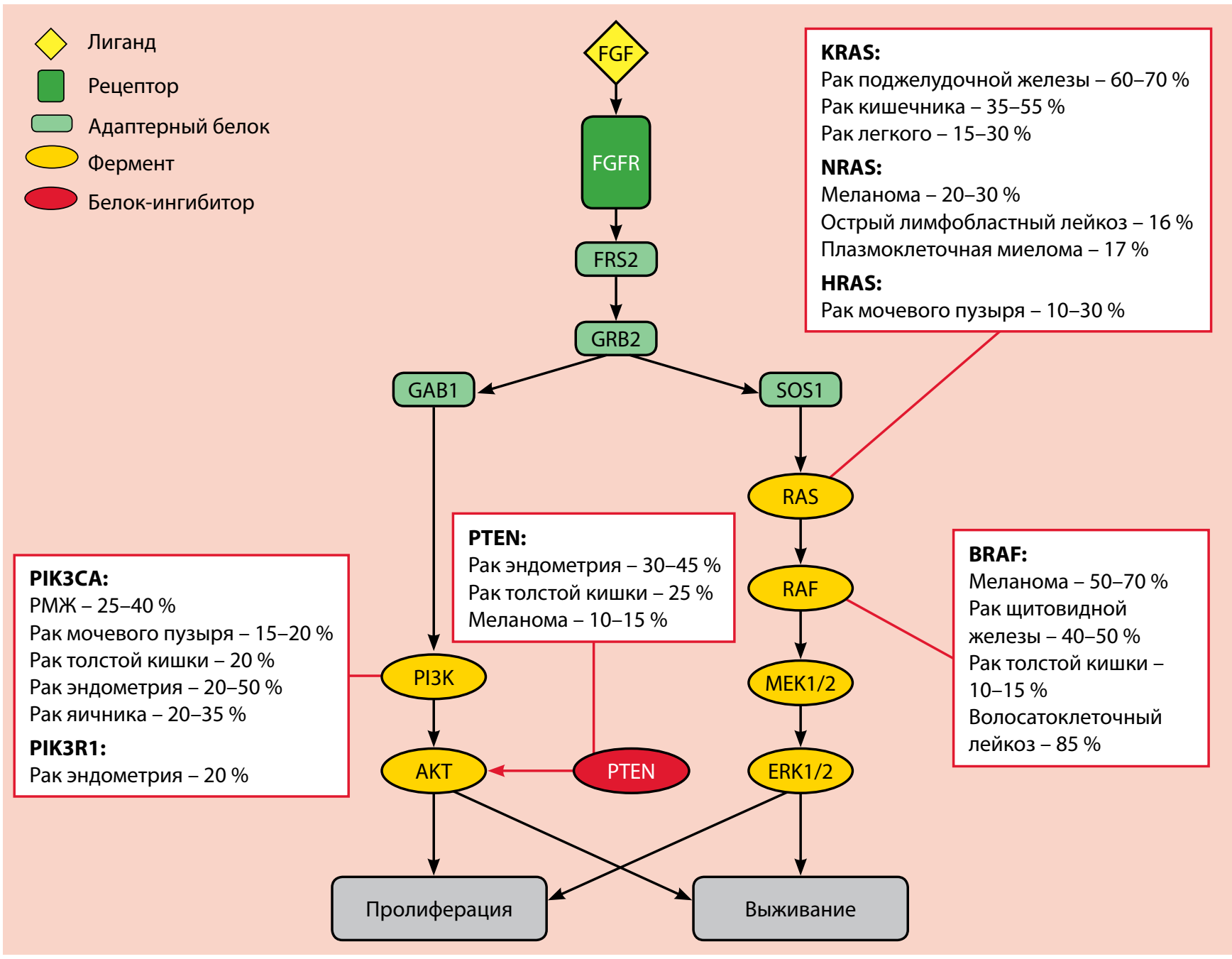

Рис. 3. Наиболее часто встречающиеся мутации в генах сигнальных путей EGFR при разных типах рака 
70 \% при раке поджелудочной железы и 55 \% при раке толстой кишки. Частота встречаемости мутаций в гене $B R A F$ при меланоме составляет 50-70\%. Мутации в гене $P I 3 K$ встречаются с достаточно высокой частотой при различных типах рака. Кроме того, для различных опухолей характерны также мутации в гене $P T E N$, являющемся негативным регулятором пути PI3K/AKT. Подобные цифры позволяют предположить, что, помимо задачи разработки эффективных ингибиторов FGF и FGFR для лечения онкологических заболеваний, перед исследователями может также встать задача преодоления резистентности к такой терапии у пациентов, являющихся носителями мутаций в белках нижележащих сигнальных путей.

\section{Заключенше}

Определение значимости комплекса FGF-FGFR в канцерогенезе и прогрессировании опухолей различной нозологии послужило толчком к появлению работ, посвященных поиску возможностей лекарственного воздействия на данный сигнальный путь. С точки зрения терапевтического воздействия на сигнальный путь FGFR возможно не только блокировать лиганды и рецепторы к FGF, но и нижележащие молекулы сигнальных путей, активируюшихся под действием FGFR. Несмотря на то, что анти-FGFR-терапия находится на раннем этапе клинического изучения в онкологии, уже сейчас видны определенные трудности в реализации данного лечебного подхода, такие как высокая токсичность, не всегда валидированная мишень воздействия, необходимость отбора пациентов в зависимости от активности FGF-FGFR-пути, а также в зависимости от наличия мутаций в молекулах нижележащих сигнальных путей. Однако улучшение фармацевтической составляющей в создании препаратов с избирательной анти-FGFR-активностью и развитие методов ранней молекулярной диагностики позволит преодолеть все сложности.

\section{Л}

1. Itoh N. The Fgf families in humans, mice, and zebrafish: their evolutional processes and roles in development, metabolism, and disease. Biol Pharm Bull 2007;30(10):1819-25. 2. Ornitz D. M., Xu J., Colvin J.S. et al. Receptor specificity of the fibroblast growth factor family. J Biol Chem 1996;271(25):15292-7. 3. Turner N., Grose R. Fibroblast growth factor signalling: from development to cancer. Nat Rev Cancer 2010;10(2):116-29. 4. Katoh M., Nakagama H. FGF receptors: cancer biology and therapeutics. Med Res Rev 2014;34(2):280-300.

5. Beenken A., Mohammadi M. The FGF family: biology, pathophysiology and therapy. Nat Rev Drug Discov 2009;8(3):235-53.

6. Bryant D. M., Stow J. L. Nuclear translocation of cell-surface receptors: lessons from fibroblast growth factor. Traffic 2005;6(10):947-54.

7. Imamura T., Engleka K., Zhan X. et al. Recovery of mitogenic activity of a growth factor mutant with a nuclear translocation sequence. Science 1990;249(4976):1567-70. 8. Bikfalvi A., Klein S., Pintucci G., Rifkin D. B. Biological roles of fibroblast growth factor-2. Endocr Rev 1997;18(1): $26-45$.

9. Miller D. L., Ortega S., Bashayan O. et al. Compensation by fibroblast growth factor 1 (FGF1) does not account for the mild phenotypic defects observed in FGF2 null mice. Mol Cell Biol 2000;20(6):2260-8. 10. Dono R., Texido G., Dussel R. et al. Impaired cerebral cortex development and blood pressure regulation in FGF-2-deficient mice. EMBO J 1998;17(15):4213-25.
11. Simons M., Horowitz A.

Syndecan-4-mediated signalling. Cell Signal 2001;13(12):855-62.

12. Ong S. H., Guy G. R., Hadari Y. R. et al. FRS2 proteins recruit intracellular signaling pathways by binding to diverse targets on fibroblast growth factor and nerve growth factor receptors. Mol Cell Biol 2000;20(3):979-89.

13. Ong S. H., Hadari Y. R., Gotoh N. et al. Stimulation of phosphatidylinositol 3-kinase by fibroblast growth factor receptors is mediated by coordinated recruitment of multiple docking proteins. Proc Natl Acad Sci USA 2001;98(11):6074-9.

14. Lin N., Chen S., Pan W. et al. NP603, a novel and potent inhibitor of FGFR1 tyrosine kinase, inhibits hepatic stellate cell proliferation and ameliorates hepatic fibrosis in rats. Am J Physiol Cell Physiol 2011;301(2):C469-77.

15. Meloche S., Pouyssegur J. The ERK1/2 mitogen-activated protein kinase pathway as a master regulator of the G1- to S-phase transition. Oncogene 2007;26(22):3227-39. 16. Koziczak M., Holbro T., Hynes N. E. Blocking of FGFR signaling inhibits breast cancer cell proliferation through downregulation of D-type cyclins. Oncogene 2004;23(20):3501-8.

17. Lee J. G., Kay E. P. PI 3-kinase/Rac1 and ERK1/2 regulate FGF-2-mediated cell proliferation through phosphorylation of p27 at Ser 10 by KIS and at Thr187 by

Cdc25A/Cdk2. Invest Ophthalmol Vis Sci 2011;52(1):417-26.

18. Miyake M., Ishii M., Koyama N. et al. 1-tert-butyl-3-[6-(3,5-dimethoxy-phenyl)2-(4-diethylamino-butylamino)-pyrido- [2,3-d]-pyrimidin-7-yl-urea (PD173074), a selective tyrosine kinase inhibitor of fibroblast growth factor receptor-3 (FGFR3), inhibits cell proliferation of bladder cancer carrying the FGFR3 gene mutation along with up-regulation of $\mathrm{p} 27 / \mathrm{Kip} 1$ and $\mathrm{G} 1 / \mathrm{G} 0$ arrest. J Pharmacol Exp Ther 2010;332(3):795-802.

19. Pardo O. E., Arcaro A., Salerno G. et al. Fibroblast growth factor-2 induces translational regulation of $\mathrm{Bcl}-\mathrm{XL}$ and $\mathrm{Bcl}-2$ via a MEK-dependent pathway: correlation with resistance to etoposideinduced apoptosis. J Biol Chem 2002;277(14):12040-6.

20. Goetz R., Mohammadi M. Exploring mechanisms of FGF signalling through the lens of structural biology. Nat Rev Mol Cell Biol 2013;14(3):166-80.

21. Balmanno K., Cook S. J. Tumour cell survival signalling by the ERK1/2 pathway. Cell Death Differ 2009;16(3):368-77. 22. Mohammadi M., Honegger A. M., Rotin D. et al. A tyrosine-phosphorylated carboxy-terminal peptide of the fibroblast growth factor receptor $(\mathrm{Flg})$ is a binding site for the $\mathrm{SH} 2$ domain of phospholipase C-gamma 1. Mol Cell Biol 1991;11(10):5068-78. 23. Hart K. C., Robertson S. C., Kanemitsu M.Y. et al. Transformation and Stat activation by derivatives of FGFR1, FGFR3, and FGFR4. Oncogene 2000;19(29):3309-20.

24. Smith T. G., Karlsson M., Lunn J. S. et al. Negative feedback predominates over crossregulation to control ERK MAPK activity in response to FGF signalling in embryos. FEBS Lett 2006;580(17):4242-5. 
25. Mason J. M., Morrison D. J., Basson M. A., Licht J. D. Sprouty proteins: multifaceted negative-feedback regulators of receptor tyrosine kinase signaling. Trends Cell Biol 2006;16(1):45-54.

26. Kovalenko D., Yang X., Nadeau R.J. et al. Sef inhibits fibroblast growth factor signaling by inhibiting FGFR1 tyrosine phosphorylation and subsequent ERK activation. J Biol Chem 2003;278(16): 14087-91.

27. Baird A., Böhlen P. Fibroblast growth factors, in Peptide growth factors and their receptors I. Springer, 1990. Pp. 369-418. 28. Matthews D. J., Gerritsen M. E. Targeting protein kinases for cancer therapy. John Wiley \& Sons, 2011.

29. Федянин М. Ю., Хмелькова Д. Н., Серебрийская Т. С. и др. Рецепторы фактора роста фибробластов при злокачественных опухолях.

Злокачественные опухоли 2014;(4). http://www.malignanttumours.org/. [Fedyanin M. Yu., Khmelkova D. N., Serebriyskaya T.S. et al. Receptors of fibroblast growth factor at malignant tumours.. Zlokachestvennye opukholi = Malignant Tumours 2014;(4).

http://www.malignanttumours.org/.

(In Russ.)].

30. Byron S. A., Gartside M. G., Wellens C. et al. Inhibition of activated fibroblast growth factor receptor 2 in endometrial cancer cells induces cell death despite PTEN abrogation. Cancer Res 2008;68(17):6902-7.

31. Kunii K., Davis L., Gorenstein J. et al. FGFR2-amplified gastric cancer cell lines require FGFR2 and Erbb3 signaling for growth and survival. Cancer Res 2008;68(7):2340-8. 32. Knights V., Cook S. J. De-regulated FGF receptors as therapeutic targets in cancer. Pharmacol Ther 2010;125(1):105-17. 33. Sarker D., Molife R., Evans T. R. et al. A phase I pharmacokinetic and pharmacodynamic study of TKI258, an oral, multitargeted receptor tyrosine kinase inhibitor in patients with advanced solid tumors. Clin Cancer Res 2008;14(7):2075-81.

34. Taylor S. K., Chia S., Dent S. et al. A phase II study of pazopanib in patients with recurrent or metastatic invasive breast carcinoma: a trial of the Princess Margaret Hospital phase II consortium. Oncologist 2010;15(8):810-8.

35. Cristofanilli M., Johnston S. R., Manikhas A. et al. A randomized phase II study of lapatinib + pazopanib versus lapatinib in patients with HER2+ inflammatory breast cancer. Breast Cancer Res Treat 2013;137(2):471-82

36. Brady J., Corrie P., Chau I. et al. An open-label study of the safety and tolerability of pazopanib in combination with FOLFOX6 or CapeOx in patients with colorectal cancer. Invest New Drugs 2013;31(5):1228-35. 37. Patel R. R., Sengupta S., Kim H. R. et al. Experimental treatment of oestrogen receptor (ER) positive breast cancer with tamoxifen and brivanib alaninate,a VEGFR-2/FGFR-1

kinase inhibitor: a potential clinical

application of angiogenesis inhibitors.

Eur J Cancer 2010;46(9):1537-53.

38. Shiang C. Y., Qi Y., Wang B. et al. Amplification of fibroblast growth factor receptor-1 in breast cancer and the effects of brivanib alaninate. Breast Cancer Res Treat 2010;123(3):747- 55

39. Siu L., Shapiro J. D., Jonker D. J. et al. NCIC Clinical Trials Group and AGITG: Phase III randomized trial of cetuximab (CET) plus either brivanib alaninate (BRIV) or placebo in patients (pts) with metastatic (MET) chemotherapy refractory K-RAS wild-type (WT) colorectal carcinoma (CRC): The NCIC Clinical Trials Group and AGITG CO. 20 trial. J Clin Oncol 2012;30

(Suppl 4):3504.

40. Dempke W. C., Zippel R. Brivanib, a novel dual VEGF-R2/bFGF-R inhibitor. Anticancer Res 2010;30(11):4477-83. 41. Wilson D., Hoff P. M., Schmoll H. et al. Application of adaptive study designs: Phase II and III results from the cediranib (CED) HORIZON (HZ) II and III studies. J Clin Oncol 2011;29(suppl):abstr 3633.

42. Raja F., Perren T., Raja F. A. et al.

Randomized double-blind phase III trial of cediranib (AZD 2171) in relapsed platinum sensetive ovarisn cancer: results of the ICON6 trial. Int J Cynecol Cancer 2013;23(8). 43. Okamoto I., Kaneda H., Satoh T. et al. Phase I safety, pharmacokinetic, and biomarker study of BIBF 1120, an oral triple tyrosine kinase inhibitor in patients with advanced solid tumors. Mol Cancer Ther 2010;9(10):2825-33.

44. Mross K., Stefanic M., Gmehling D. et al. Phase I study of the angiogenesis inhibitor BIBF 1120 in patients with advanced solid tumors. Clin Cancer Res 2010;16(1):311-9. 45. du Bois A., Huober J., Stopfer P. et al. A phase I open-label dose-escalation study of oral BIBF 1120 combined with standard paclitaxel and carboplatin in patients with advanced gynecological malignancies. Ann Oncol 2010;21(2):370-5.

46. Kropff M., Kienast J., Bisping G. et al. An open-label dose-escalation study of BIBF 1120 in patients with relapsed or refractory multiple myeloma. Anticancer Res 2009;29(10):4233-8.

47. Lee C., Attard G., Poupard L. et al. A phase I study of BIBF 1120, an orally active triple angiokinase inhibitor (VEGFR, PDGFR, FGFR) in patients with advanced solid malignancies. J Clin Oncol 2005;23:3054. 48. Reck M., Kaiser R., Eschbach C. et al. A phase II double-blind study to investigate efficacy and safety of two doses of the triple angiokinase inhibitor BIBF 1120 in patients with relapsed advanced non-small-cell lung cancer. Ann Oncol 2011;22(6):1374-81. 49. Ledermann J. A., Hackshaw A., Kaye S. et al. Randomized phase II placebocontrolled trial of maintenance therapy using the oral triple angiokinase inhibitor BIBF
1120 after chemotherapy for relapsed ovarian cancer. J Clin Oncol 2011;29(28):3798-804. 50. Bouche O., Maindrault-Goebel F., Ducreux M. et al. Phase II trial of weekly alternating sequential BIBF 1120 and afatinib for advanced colorectal cancer. Anticancer Res 2011;31(6):2271-81.

51. Molife R., de Bono J. S., Bell S. et al. A phase II trial to compare BIBF 1120 or BIBW 2992 monotherapy versus a combination of sequential administration of both medications in patients with hormone refractory prostate cancer (HRPC); ASCO Genitourinary Cancers Symposium. Orlando FLA, USA, 2009.

52. Du Bois A., Kristensen G., Ray-Coquard I. et al. AGO-OVAR 12: a randomized placebocontrolled GCIG/ENGOT-Intergroup phase III trial of standard frontline chemotherapy $+/$ - nintedanib for advanced ovarian cancer Int J Gynecol Cancer 2013;23(8 Suppl):7-8. 53. Reck M., Kaiser R., Mellemgaard A et al. Docetaxel plus nintedanib versus docetaxel plus placebo in patients with previously treated non-small-cell lung cancer(LUME-Lung 1): a phase 3, doubleblind, randomised controlled trial. Lancet Oncol 2014;15(2):143-55.

54. Konecny G. N., Finkler N., Garcia A. A. et al. Phase 2 study of second-line dovitinib (TKI258) in patients with fibroblast growth factor receptor 2 (FGFR2) - mutated or nonmutated advanced and/or metastatic endometrial cancer. ESMO 2014. LBA27. 55. Brooks A. N., Kilgour E., Smith P. D. Molecular pathways: fibroblast growth factor signaling: a new therapeutic opportunity in cancer. Clin Cancer Res 2012;18(7): 1855-62.

56. Dey J.H., Bianchi F., Voshol J. et al. Targeting fibroblast growth factor receptors blocks PI3K/AKT signaling, induces apoptosis, and impairs mammary tumor outgrowth and metastasis. Cancer Res 2010;70(10):4151-62.

57. Koziczak M., Hynes N. E. Cooperation between fibroblast growth factor receptor-4 and ErbB2 in regulation of cyclin D1 translation. J Biol Chem 2004;279(48):50004-11. 58. Andre F. D. F., Daly F., Azim H. A. et al. FINESSE: An open, three-cohort, phase II trial testing oral administration of lucitanib in patients with FGFR1-amplified or nonamplified estrogen receptor-positive metastatic breast cancer. J Clin Oncol 2014;32(5s):abstr TPS1134

59. Gozgit J. M., Wong M. J., Moran L. et al. Ponatinib (AP24534), a multitargeted panFGFR inhibitor with activity in multiple FGFR-amplified or mutated cancer models. Mol Cancer Ther 2012;11(3):690-9.

60. Gild M. L., Bullock M., Robinson B. G., Clifton-Bligh R. Multikinase inhibitors: a new option for the treatment of thyroid cancer. Nat Rev Endocrinol 2011;7(10):617-24. 61. Gavine P. R., Mooney L., Kilgour E. et al. AZD4547: an orally bioavailable, potent, and selective inhibitor of the fibroblast growth 
노 factor receptor tyrosine kinase family. Cancer Res 2012;72(8):2045-56.

62. Guagnano V., Furet P., Spanka C. et al.

Discovery of 3-(2,6-dichloro-3,5-dimethoxyphenyl)-1-\{6-[4-(4-ethyl-piperazin-1-yl)phenylamin o]-pyrimidin-4-yl\}-1-methylurea (NVP-BGJ398), a potent and selective inhibitor of the fibroblast growth factor receptor family of receptor tyrosine kinase. J Med Chem 2011;54(20):7066-83.

63. Martinez-Torrecuadrada J., Cifuentes G., López-Serra P. et al. Targeting the extracellular domain of fibroblast growth factor receptor 3 with human single-chain Fv antibodies inhibits bladder carcinoma cell line proliferation. Clin Cancer Res 2005;11(17):6280-90.
64. Qing J., Du X., Chen Y. et al. Antibodybased targeting of FGFR3 in bladder carcinoma and $\mathrm{t}(4 ; 14)$ - positive multiple myeloma in mice. J Clin Invest 2009;119(5):1216-29. 65. Zhang H., Lorianne M., Baker K. et al. FP-1039 (FGFR1: Fc), a soluble FGFR1 receptor antagonist, inhibits tumor growth and angiogenesis. Mol Cancer Ther 2007;6(11 Suppl):B55. 